\title{
Correlation of TP53 Overexpression and Clinical Parameters with Five-Year Survival in Oral Squamous Cell Carcinoma Patients
}

Syed A. Ali ${ }^{1}$, Hamza A. Khan ${ }^{2}$, Omar Irfan ${ }^{3}$, Adeel Samad ${ }^{2}$, Yumna Mirza ${ }^{1}$, Muhammad Sohail Awan Dr 4

1. Surgery, The Aga Khan University 2. Medical College, The Aga Khan University 3. Medicine, The Aga Khan University 4. Surgery, Aga Khan University Hospital, Karachi, PAK

$\square$ Corresponding author: Omar Irfan, omarirfan1@hotmail.com

Disclosures can be found in Additional Information at the end of the article

\section{Abstract}

\section{Introduction}

TP53 mutation and overexpression have been correlated with poor survival in many cancers including oral squamous cell carcinoma (OSCC). We aim to understand the role of TP53 overexpression in OSCC in our population and correlate it with five-year survival to test its viability as a prognostic marker for OSCC patients.

\section{Materials and methods}

Patients with biopsy proven OSCC at Aga Khan University Hospital from January 2000 to January 2008 were recruited. Immunohistochemistry was used to establish TP53 status and the results were published. Following up on these patients, five-year data were collected and correlated with TP53 status and other clinicopathologic parameters.

\section{Results}

Overexpression of TP53 was not significantly associated with five-year survival (hazard ratio [HR]: 1.543; 95\% CI: 0.911-2.612; $\mathrm{p}=0.107)$.

\section{Conclusion}

Although we had proven statistical relevance when correlated with overall survival in our previous study, we were unable to extend the same relevance to TP53 overexpression when it comes to five-year survival.

Received 05/28/2017

Review began 06/07/2017 Review ended 06/18/2017 Published 06/27/2017

(C) Copyright 2017

Ali et al. This is an open access article distributed under the terms of the Creative Commons Attribution License CC-BY 3.0., which permits unrestricted use, distribution, and reproduction in any medium, provided the original author and source are credited.
Categories: Otolaryngology, Pathology, Radiation Oncology

Keywords: oral squamous cell carcinoma (oscc), tp53, 5 year survival

\section{Introduction}

Oral squamous cell carcinoma (OSCC) is ranked as the eighth most common cancer, with global incidence being 299,050 and 12,720 in Pakistan in 2012 [1]. An alarming statistic is that Karachi, the largest city of Pakistan, bears the highest incidence of oral cavity cancer in the world [2]. Moreover, a study conducted in Karachi stated that OSCC among low-income families had increased by 200\% from 1998 to 2002 . According to the reports published by Pakistan 
Medical Research Council (PMRC), OSCC is the most common cancer among males and ranks second highest among females [3]. The worldwide mortality for 2012 was 145,350, stressing upon the need for effective management of the disease.

Emphasizing on the importance of this disease and its devastating consequences on our population, research in the developmental mechanisms of OSCC holds immense importance. The progress of OSCC at the molecular level is still unclear but latest developments present it to be the result of environmental factors causing mutations in oncogenes and tumor suppressor genes, particularly those involved in cell proliferation, differentiation, apoptosis and deoxyribonucleic acid (DNA) repair [4].

Several risk factors are known to aid in the pathogenesis of OSCC: smoking, alcohol consumption, chewing of betel quid and areca nut, and human papillomavirus infection [5]. Approximately 600 million people engage in betel quid chewing worldwide [5], making it the fourth most common addictive substance used, following tobacco, alcohol, and caffeine [6]. A study piloted in a squatter settlement of Karachi exposed that $40 \%$ of the population used betel nut and tobacco regularly [7].

Among all the mutations found in OSCC, the TP53 tumor suppressor gene is most frequently mutated [8-9]. The TP53 gene is located on the short arm of chromosome 17 and prevents cancer formation by maintaining genomic stability and regulating the cell cycle. Different kinds of stresses including oncogenic stimuli, ionizing radiation, UV radiation, hypoxia, cytokines and growth factors can activate the TP53 through different pathways [10]. As the "guardian of the genome"- p53 protein can initiate DNA repair proteins and stop the cell cycle at the G1/S regulation point when the DNA is damaged or activate apoptosis if the DNA is damaged beyond repair. When mutated, it allows cells to progress through DNA damage checkpoints and these cells are allowed to replicate along with their harmful mutations.

It has been established by the International Cancer Genome Consortium that the missense mutation is the most commonly occurring type (79\%) among all TP53 mutations [11]. Mutations in TP53 make it more stable and hence easy to detect by immunohistochemistry [12]. However, any loss-of-function mutation in the TP53 does not directly transform the cells into neoplastic cells as loss of guardian function has no direct effect on proliferation. Instead, it permits the DNA to get damaged easily leading to mutations, acquisition of oncogenes, and neoplastic activity.

To date, even after intense research in management options, the five-year survival rate for OSCC has not increased significantly [13]. There have been very few studies on OSCC fiveyear survival worldwide and no studies to date in Pakistan, to the best of our knowledge. There have been a number of studies on one- and two-year survival but it is difficult to use such data to form conclusions in cancers like OSCC as these patients usually live for up to more than two years which stresses the need for five-year survival studies. Furthermore, the association of TP53 mutation and five-year survival of OSCC patients is still unclear. Correlation of TP53 mutation with gender, age, OSCC risk factors like alcohol and tobacco, site and grading are currently being established in different researches around the world in order to provide detailed information on OSCC patient prognosis at the time of presentation.

We have previously carried out and published a study discussing TP53 expression in terms of overall survival which concerned the same patient data set [14]. Five-year follow-up data for these patients was unavailable at the time of that study, as they had been freshly recruited, thus the aim of that study was to understand TP53 expression in terms of overall survival, as the duration of survival varied greatly among the patients. Subsequently, the aim of this study is to continue work on these patients and establish any and all such correlations between TP53 


\section{Cureus}

mutation and OSCC patient prognosis using a fixed five-year survival rate as it is the optimum method to validate prognostic use of any marker.

\section{Materials And Methods}

The study was a case series including 140 patients with primary OSCC who had been diagnosed and treated at Aga Khan University Hospital (AKUH), Karachi, Pakistan from January 2000 to January 2008. The study was approved by the Ethical Review Committee at AKUH and written informed consent was taken from all patients prior to their induction in the study. Inclusion criteria consisted of complete clinicopathologic data and presence of five-year follow-up data. Clinicopathologic information on each case including gender, age, TP53 overexpression, use of betel nut and/or other substances, smoking or alcohol consumption either alone or in different combinations, the site of OSCC, American Joint Committee on Cancer (AJCC) staging, tumor size, nodal involvement and metastasis was collected from our previously conducted study [14]. Additional five-year follow-up was obtained for all patients and they were classified as either alive or dead after 60 months. Immunohistochemistry was used in our previously reported study to assess TP53 overexpression using primary antibody TP53 (mouse monoclonal antiTP53, clone DO-7, Dako Cytomation, diluted 1:50).

The results were recorded by the study investigators and data was analyzed using SPSS version 19 (IBM, NY, USA). Potential associations between demographic, histological, clinical parameters and five-year survival were assessed. Follow-up times for each patient were measured in months and mean survival was calculated from the date of diagnosis until death or for 60 months, whichever occurred sooner. Univariate Cox analysis was done to investigate the effect of clinicopathologic factors on mean five-year survival and a multivariate analysis was done for AJCC staging and TP53 positivity. A Kaplan-Meier curve was plotted to assess the event point distribution over a period of 60 months.

\section{Results}

\section{Patient characteristics}

The total sample size was 140, with 69 patients expiring (event) and 71 alive (censored) at the end of 60 months. In our study, 82 patients (59\%) were males and 58 (41\%) were females with a male-female ratio of $1.4: 1$ and 112 (80\%) patients were $>40$ years of age. The most frequently occurring primary lesion location was cheek (86) followed by tongue (54), mandible (36), palate (14), retromandible (17) and the floor of the mouth (14). Additionally, the highest number of patients presented with AJCC stage II disease (34\%), followed by stage III (27\%), stage IV (22\%) and stage I (19\%). Based on the disease stage, 82 (59\%) patients were treated with surgery and radiation both while 58 (41\%) were treated with surgery alone. Most commonly used addictive substance for our patients was betel quid, followed by tobacco. Table 1 shows the demographic details of the patients.

\begin{tabular}{|c|c|c|c|c|c|c|c|}
\hline & & \multicolumn{2}{|c|}{ Event $(n=69)$} & \multicolumn{2}{|c|}{ Censored $(n=71)$} & \multicolumn{2}{|c|}{ Total $(n=140)$} \\
\hline & & Count & $\begin{array}{l}\text { Column N } \\
\%\end{array}$ & Count & $\begin{array}{l}\text { Column N } \\
\%\end{array}$ & Count & $\begin{array}{l}\text { Column N } \\
\%\end{array}$ \\
\hline \multirow{2}{*}{ Gender } & Male & 40 & $58.0 \%$ & 42 & $59.2 \%$ & 82 & $58.6 \%$ \\
\hline & Female & 29 & $42.0 \%$ & 29 & $40.8 \%$ & 58 & $41.4 \%$ \\
\hline \multirow{2}{*}{ Age group } & $<40$ years & 11 & $15.9 \%$ & 17 & $23.9 \%$ & 28 & $20.0 \%$ \\
\hline & $>=40$ years & 58 & $84.1 \%$ & 54 & $76.1 \%$ & 112 & $80.0 \%$ \\
\hline
\end{tabular}




\section{Cureus}

TP53 value

$\begin{array}{lllllll}\text { Positive } & 49 & 71.0 \% & 45 & 63.4 \% & 94 & 67.1 \% \\ \text { Negative } & 20 & 29.0 \% & 26 & 36.6 \% & 46 & 32.9 \% \\ \text { Mild } & 8 & 11.6 \% & 11 & 15.5 \% & 19 & 13.6 \% \\ \text { Moderate } & 15 & 21.7 \% & 7 & 9.9 \% & 22 & 15.7 \% \\ \text { Strong } & 26 & 37.7 \% & 27 & 38.0 \% & 53 & 37.9 \% \\ \text { Negative } & 20 & 29.0 \% & 26 & 36.6 \% & 46 & 32.9 \%\end{array}$

Histological classification of

W-D-SCC

26

$37.7 \%$

29

$40.8 \%$

$55 \quad 39.3 \%$

tumor

M-D-SCC

$41 \quad 59.4 \%$

38

$53.5 \%$

$79 \quad 56.4 \%$

P-D-SCC

$2.9 \%$

4

$4.1 \%$

6

$4.3 \%$

I

9

AJCC_STAGE

II

18

$13.0 \%$

18

$25.4 \%$

$27 \quad 19.3 \%$

III

$26.1 \%$

26

$36.6 \%$

$44 \quad 31.4 \%$

22

$31.9 \%$

16

$22.5 \%$

$38 \quad 27.1 \%$

20

$29.0 \%$

$15.5 \%$

31

$22.1 \%$

Smoking

Yes

26

$37.7 \%$

$41.7 \%$

$51 \quad 36.4 \%$

43

$62.3 \%$

$58.3 \%$

$89 \quad 63.6 \%$

Betel quid chewer

Yes

43

$62.3 \%$

$54.9 \%$

$82 \quad 58.6 \%$

26

$37.7 \%$

$45.1 \%$

$48 \quad 34.4 \%$

Tobacco

Yes

20

$29.0 \%$

$32.4 \%$

$43 \quad 30.7 \%$

$\begin{array}{lll}49 & 71.0 \% & 48\end{array}$

$67.6 \%$

$97 \quad 69.3 \%$

Cheek/tongue

No

Cheek

48

$69.6 \%$

38

$53.5 \%$

$86 \quad 61.4 \%$

Tongue

21

$30.4 \%$

33

$46.5 \%$

$54 \quad 38.6 \%$

Palate

Yes

6

$8.7 \%$

8

$11.3 \%$

$14 \quad 10.0 \%$

63

$91.3 \%$

63

$88.7 \%$

$126 \quad 90.0 \%$

Mandible

Yes

18

$26.1 \%$

18

$25.4 \%$

$36 \quad 25.7 \%$

51

$73.9 \%$

53

$74.6 \%$

$104 \quad 74.3 \%$

11

$15.9 \%$

6

$8.5 \%$

$17 \quad 12.1 \%$

Retromandibular

No

48

$69.6 \%$

51

$71.8 \%$

$99 \quad 70.7 \%$

NA

10

$14.5 \%$

14

$19.7 \%$

$24 \quad 17.1 \%$

Floor of mouth

Yes

4

$5.8 \%$

10

$14.1 \%$

$14 \quad 10.0 \%$

No

65

$94.2 \%$

$61 \quad 85.9 \%$

$12690.0 \%$

Yes

1

$1.4 \%$

$2 \quad 2.8 \%$

3

$2.1 \%$ 


\section{Cureus}

Tonsil

Nodal status physical

Palpable node

68

69

$97.2 \%$

137

$97.9 \%$

Nodal status physical

No palpable

node

$44.9 \%$

$26 \quad 36.6 \%$

$57 \quad 40.7 \%$

Single/multiple nodes

20

$55.1 \%$

45

$63.4 \%$

83

$59.3 \%$

Single/multiple nodes

Multiple

$29.0 \%$

19

$26.8 \%$

39

$27.9 \%$

11

$15.9 \%$

7

$9.9 \%$

18

$12.9 \%$

NA

38

$55.1 \%$

45

$63.3 \%$

83

$59.3 \%$

$\mathrm{T} 1$

12

$17.4 \%$

21

$29.6 \%$

33

$23.6 \%$

Final T stage

T2

31

$44.9 \%$

33

$46.5 \%$

$64 \quad 45.7 \%$

T3

12

$17.4 \%$

10

$14.1 \%$

22

$15.7 \%$

T4

$20.3 \%$

7

$9.8 \%$

21

$15.0 \%$

NO

43

$62.3 \%$

59

$83.1 \%$

102

$72.9 \%$

Final $\mathrm{N}$ stage

N1

18

$26.1 \%$

8

$11.3 \%$

$26 \quad 18.6 \%$

N2a

$2.9 \%$

$1.4 \%$

3

$2.1 \%$

N2b

$8.7 \%$

$4.2 \%$

9

$6.4 \%$

Final $\mathrm{M}$ stage

MO

69

$100.0 \%$

71

$100.0 \%$

140

$100.0 \%$

Negative

27

$39.1 \%$

44

$62.0 \%$

$71 \quad 50.7 \%$

Neck pathology

Positive

25

$36.2 \%$

13

$18.3 \%$

38

$27.1 \%$

ND

17

$24.6 \%$

14

$19.7 \%$

31

$22.1 \%$

TABLE 1: Patient demographics at five-year follow-up $(n=140)$.

Out of 140 tumors, 94 (67\%) patients were TP53 positive and 46 (33\%) patients were TP53 negative. TP53 overexpression was not significantly correlated with any clinicopathologic parameters tested, such as AJCC staging, habits, histology and final T and N stages. A total of 54 patients presented with tongue as the primary site of tumor, with 51 patients having tumor in the anterior tongue, five in the posterior and two patients having both. However, a significant association was observed between the anterior tongue as the site of tumor and TP53 positivity $(\mathrm{p}=0.038)$. Table 2 shows TP53 expression and clinicopathologic parameters. 


\section{Cureus}

\begin{tabular}{|c|c|c|c|c|c|}
\hline Characteristic & & $\begin{array}{l}\text { P53 overexpression } \\
\text { positive }\end{array}$ & $\begin{array}{l}\text { P53 overexpression } \\
\text { negative }\end{array}$ & $\begin{array}{l}\text { Pearson Chi- } \\
\text { Square value }\end{array}$ & $\begin{array}{l}\mathrm{p} \text { - } \\
\text { value }\end{array}$ \\
\hline \multirow[t]{4}{*}{ AJCC staging } & Stage I & 21 & 6 & \multirow{4}{*}{5.247} & \multirow{4}{*}{0.155} \\
\hline & Stage II & 33 & 11 & & \\
\hline & Stage III & 22 & 16 & & \\
\hline & Stage IV & 18 & 13 & & \\
\hline \multirow[t]{3}{*}{ Habits } & Smoking/tobacco & 35 & 16 & 0.090 & 0.956 \\
\hline & Pan/supari & 57 & 25 & 0.612 & 0.736 \\
\hline & Naswar/chalia/gutka & 28 & 15 & 0.242 & 0.886 \\
\hline \multirow{4}{*}{ Final T stage } & Stage I & 23 & 10 & \multirow{4}{*}{4.439} & \multirow{4}{*}{0.218} \\
\hline & Stage II & 47 & 17 & & \\
\hline & Stage III & 11 & 11 & & \\
\hline & Stage IV & 13 & 8 & & \\
\hline \multirow{3}{*}{ Final $\mathrm{N}$ stage } & No & 70 & 32 & \multirow{3}{*}{0.560} & \multirow{3}{*}{0.756} \\
\hline & N1 & 17 & 9 & & \\
\hline & N2 & 7 & 5 & & \\
\hline \multirow[t]{3}{*}{ Histology } & W-D-SCC & 38 & 17 & \multirow{3}{*}{0.894} & \multirow{3}{*}{0.640} \\
\hline & M-D-SCC & 53 & 26 & & \\
\hline & P-D-SCC & 3 & 3 & & \\
\hline \multirow[t]{7}{*}{ Site of tumor } & Anterior tongue & 30 & 23 & 4.294 & 0.038 \\
\hline & Posterior tongue & 4 & 1 & 0.389 & 0.533 \\
\hline & Palate & 10 & 4 & 0.130 & 0.719 \\
\hline & Mandible & 23 & 13 & 0.233 & 0.630 \\
\hline & Retromandibular & 11 & 6 & 0.387 & 0.824 \\
\hline & Floor of mouth & 9 & 5 & 0.058 & 0.810 \\
\hline & Tonsil & 3 & 0 & 1.500 & 0.221 \\
\hline
\end{tabular}

TABLE 2: Correlation of P53 overexpression and clinicopathologic parameters.

Furthermore, AJCC staging, final N stage and neck pathology were found statistically significant on univariate analysis $(\mathrm{p}=0.003, \mathrm{p}<0.001$ and $\mathrm{p}=0.003$, respectively) (Table 3). Moreover, AJCC staging remained significant $(\mathrm{p}=0.003)$ on multivariate analysis using COX 


\section{Cureus}

regression, while TP53 persisted statistically insignificant.

\section{Mean and median survival time}

AJCC stage I was associated with significantly longer survival (49.9 months, 95\% CI: 41.9-57.9) as compared to stage IV (31.8 months, $95 \%$ CI: 22.9-40.6) as shown in Table 3. Additionally, the absence of neck pathology displayed significantly longer survival (50.2 months, 95\% CI: 45.854.5). Table 3 shows the univariate and multivariate analysis. 


\section{Cureus}

\section{Univariate Analysis}

Factor

Hazard ratio or $\operatorname{Exp}(\mathrm{B})$

95.0\% Cl for $\operatorname{Exp}(\mathrm{B})$

Lower Upper

Sig.

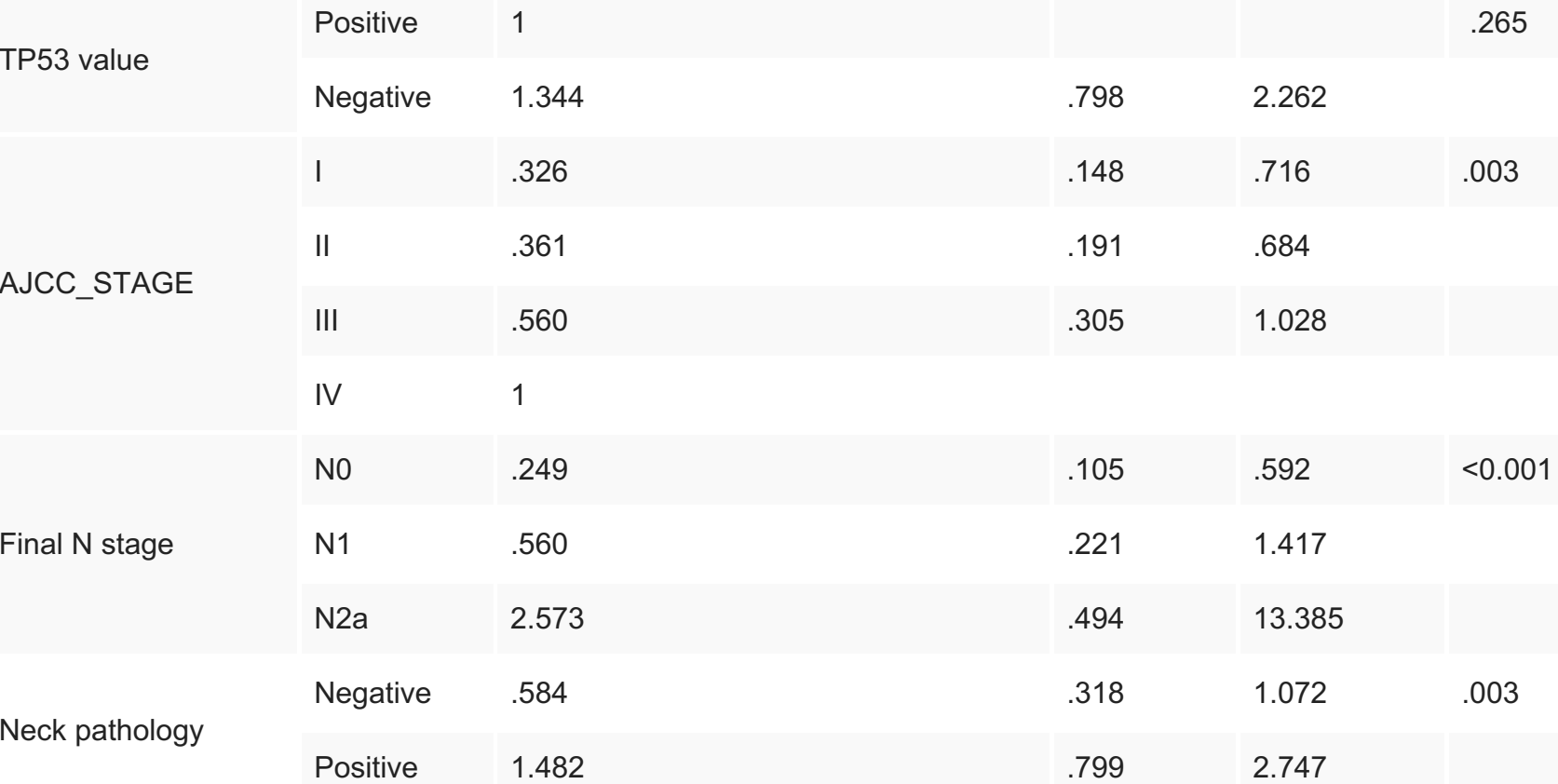

Multivariate Analysis

Adjusted hazard ratio $\operatorname{Exp}(\mathrm{B})$

95.0\% Cl for $\operatorname{Exp}(\mathrm{B})$

Lower Upper

AJCC_STAGE

II

1.823

0.837

3.972

III

3.309

1.497

7.316

TP53 value

Positive

1.543

0.911

2.612

.107

1

TABLE 3: Univariate and multivariate analysis.

\section{TP53 positivity and survival}

All clinical features in Table 1 were examined to determine any correlation with TP53 overexpression using Pearson Chi-square test and it was found that TP53 overexpression was not significantly correlated with any clinicopathologic factor (HR: 1.543; 95\% CI: 0.911-2.612, $\mathrm{p}=0.107$ ). Additionally, TP53 overexpression was also not statistically significant on univariate analysis ( $p=0.265$ ) (Table 3). Furthermore, there was no marked difference in mean survival time of TP53 positive (44.258, 95\% CI: 39.918-48.597) and TP53 negative (46.676, 95\% CI: 


\begin{tabular}{|c|c|c|c|c|c|c|c|c|}
\hline & \multicolumn{4}{|l|}{ Mean $^{a}$} & \multicolumn{4}{|l|}{ Median } \\
\hline & \multirow[b]{2}{*}{ Estimate } & \multirow{2}{*}{$\begin{array}{l}\text { Std. } \\
\text { error }\end{array}$} & \multicolumn{2}{|c|}{$95 \%$ confidence interval } & \multirow{2}{*}{ Estimate } & \multirow{2}{*}{$\begin{array}{l}\text { Std. } \\
\text { error }\end{array}$} & \multicolumn{2}{|c|}{ 95\% Confidence interval } \\
\hline & & & $\begin{array}{l}\text { Lower } \\
\text { bound }\end{array}$ & $\begin{array}{l}\text { Upper } \\
\text { bound }\end{array}$ & & & $\begin{array}{l}\text { Lower } \\
\text { bound }\end{array}$ & $\begin{array}{l}\text { Upper } \\
\text { bound }\end{array}$ \\
\hline Overall & 45.079 & 1.821 & 41.511 & 48.648 & 60.000 & .964 & 58.111 & 61.889 \\
\hline \multicolumn{9}{|c|}{ TP53 value } \\
\hline Positive & 44.258 & 2.214 & 39.918 & 48.597 & 60.000 & 2.669 & 54.769 & 65.231 \\
\hline Negative & 46.676 & 3.246 & 40.314 & 53.039 & & & & \\
\hline \multicolumn{9}{|l|}{ Positivity } \\
\hline Mild & 53.500 & 3.618 & 46.409 & 60.591 & 60.000 & & & \\
\hline Moderate & 36.994 & 4.513 & 28.148 & 45.841 & 32.000 & 3.737 & 24.676 & 39.324 \\
\hline Strong & 43.894 & 3.107 & 37.805 & 49.983 & 60.000 & 4.226 & 51.717 & 68.283 \\
\hline Negative & 46.676 & 3.246 & 40.314 & 53.039 & & & & \\
\hline \multicolumn{9}{|c|}{ AJCC_STAGE } \\
\hline I & 49.944 & 4.093 & 41.921 & 57.967 & & & & \\
\hline II & 51.417 & 2.432 & 46.652 & 56.183 & & & & \\
\hline II & 44.831 & 3.397 & 38.173 & 51.488 & 60.000 & 7.122 & 46.041 & 73.959 \\
\hline IV & 31.809 & 4.514 & 22.962 & 40.656 & 19.000 & 9.947 & 0.000 & 38.496 \\
\hline \multicolumn{9}{|c|}{ Final T stage } \\
\hline T1 & 50.711 & 3.441 & 43.966 & 57.456 & & & & \\
\hline T2 & 46.970 & 2.474 & 42.122 & 51.819 & 60.000 & 1.360 & 57.335 & 62.665 \\
\hline T3 & 43.905 & 4.815 & 34.468 & 53.342 & 60.000 & 11.148 & 38.149 & 81.851 \\
\hline T4 & 32.813 & 5.390 & 22.249 & 43.376 & 26.000 & 11.006 & 4.429 & 47.571 \\
\hline \multicolumn{9}{|c|}{ Final N stage } \\
\hline No & 49.019 & 1.938 & 45.220 & 52.818 & & & & \\
\hline $\mathrm{N} 1$ & 37.211 & 4.386 & 28.614 & 45.808 & 32.000 & 4.718 & 22.753 & 41.247 \\
\hline N2a & 12.500 & .500 & 11.520 & 13.480 & 12.000 & & & \\
\hline $\mathrm{N} 2 \mathrm{~b}$ & 28.857 & 8.385 & 12.423 & 45.292 & 19.000 & 6.547 & 6.169 & 31.831 \\
\hline $\begin{array}{l}\text { Neck } \\
\text { pathology }\end{array}$ & & & & & & & & \\
\hline
\end{tabular}




\section{Cureus}

$\begin{array}{lllllllll}\text { Negative } & 50.211 & 2.208 & 45.884 & 54.539 & & & & \\ \text { Positive } & 37.573 & 3.880 & 29.969 & 45.178 & 40.000 & 7.767 & 24.776 & 55.224 \\ \text { ND } & 42.464 & 4.081 & 34.465 & 50.462 & 60.000 & 11.262 & 37.927 & 82.073\end{array}$

TABLE 4: Mean and median survival time.

However, mild degree of positivity was found to be associated with longer survival (53.5, CI: 46.4-60.6) as compared to moderate degree of positivity (36.99, CI: 28.1-45.8). A Kaplan-Meier curve plotted as shown in Figure 1 for fixed five-year survival illustrated no significant difference in survival between TP53 positive and negative groups with Log Rank 0.239.

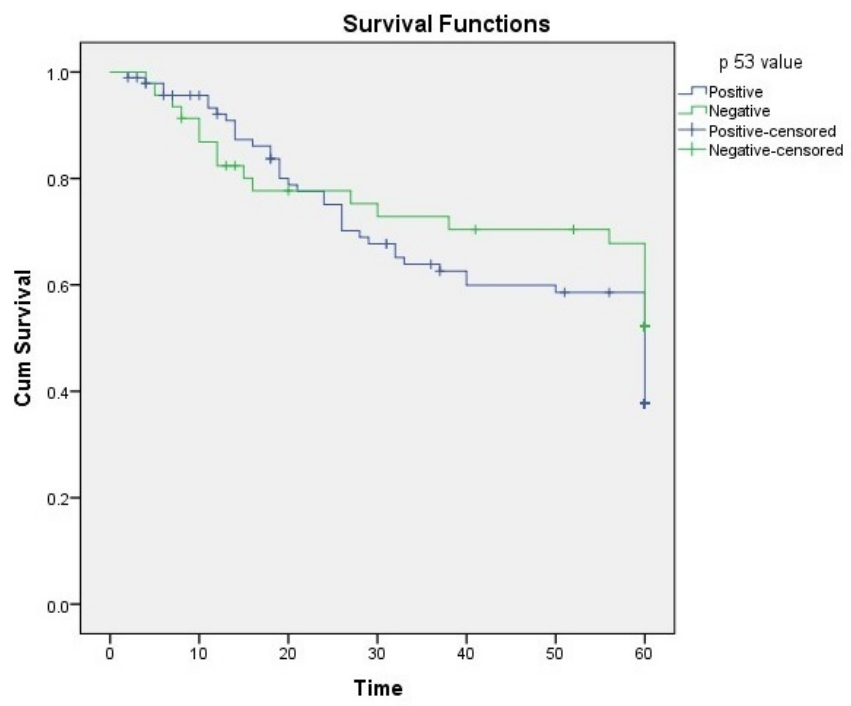

\section{FIGURE 1: Kaplan-Meier curve depicting five-year survival of p53 positive and negative oral squamous cell carcinoma (OSCC) patients.}

\section{Discussion}

The carcinogenesis of the gastrointestinal tract epithelium is an intricate process that involves abnormalities of oncogenes and tumor suppressor genes [15-16]. Even today it is not clear why patients having identical tumor grading and staging behave differently when confronted with similar treatments. This may be due to unique molecular changes resulting from differing expression of certain genes.

Western countries have a high incidence of TP53 mutations in OSCC associated with these risk factors [17] with India [18] reported to have low incidence and Taiwan [19] with high incidence from Asia. We report no association of these risk factors including smoking, tobacco and betel quid usage with TP53 over expression.

Environmental insults are known to be one of the root causes of oral cancer, considering that this malignancy occurs almost exclusively in patients with tobacco, alcohol and/or betel quid 
usage and these agents are believed to cause a synergistic carcinogenic effect on the oral cavity [5]. The independent effect of these risk factors is difficult to ascertain considering that most subjects are using a combination of these risk factors and as a result multiple conflicting outcomes have been reported.

Of all related genes, TP53 has received foremost attention: Its prevalence in head and neck squamous cell cancer varies from $30 \%$ to $70 \%$ [20]. Almost all types of cancers are reported to have TP53 mutations, from 10\% in hematopoietic malignancies to close to 100\% in high-grade serous carcinoma of the ovary [21]. According to "The TP53 website" lung cancers have the highest TP53 mutation rate (70\%) followed by colorectal (60\%) and head and neck cancers (60\%). Laryngeal squamous cell carcinoma is severely implicated in TP53 overexpression and so is the progression of non-malignant lesions to malignant ones, but for the prognostic significance of TP53 and observing its value for the entire head and neck squamous cell cancer group, results differ among studies.

In the past, there have been studies showing no correlation between TP53 expression and patient prognosis, regardless of whether the analysis involved only the invasive fronts of tumors [22], or tumors as a whole [23]. On the other hand in a study conducted on 16 patients with recurrent squamous cell carcinoma of the head and neck, a poor prognosis with positive TP53 expression was observed [24].

The presence of TP53 mutation was associated with a significantly decreased overall survival and even stronger association with disruptive mutations as shown by Poeta, et al. [25]. However, other multiple attempts have turned out inconclusive in correlating TP53 status and survival. The diversity of results may partly be due to: a diverse and small sample size, the tissue type analyzed and the methods used for analysis including antibodies, tissue treatment and the threshold set for positivity and negativity of stained sections [26].

In our study we observed that neither the histological differentiation nor the consumption of addictive substances or any other risk factors were associated with TP53 overexpression, only the location of tumor was significant for the anterior tongue showing most TP53 expression. AJCC staging, nodal status, and neck pathology were significantly associated with TP53 overexpression in univariate analysis but lost their significance in the multivariate analysis. This is in accordance with other reports including Field, et al. which reported no correlation between TP53 overexpression and any other clinicopathological parameters [27]. However, some previous reports [17] have described accumulating TP53 levels correlating with increasing histological severity and with anatomical site of the tumor.

\section{Conclusions}

An ideal marker predicting tumor prognosis should indicate tumor formation when present and should exclude such possibility on absence and to identify such a marker the five-year survival analysis is indispensable. Our previous study highlighted the importance of TP53 mutation when dealt with overall survival ranging from months to years. Following up on these patients, however, displayed that TP53 overexpression could not be held statistically significant over five-year survival. This could be due to the differing anatomical location of tumor in our patient set, the type of exposure and sample size. However, it is unlikely that a single tumor marker can predict tumor progression since the development and progression of a tumor is a cumulative response to various factors. Therefore, it is equally important to look at the status of other factors closely related to TP53. Nevertheless, the TP53 pathway is a very important one in head and neck squamous cell cancer pathogenesis and also potentially in its management. We believe that TP53 overexpression estimation may eventually prove useful as a routine component of tumor assessment along with tumor staging. 


\section{Additional Information \\ Disclosures}

Human subjects: Consent was obtained by all participants in this study. The study was approved by the Ethical Review Committee at AKUH and written informed consent was taken from all patients prior to their induction in the study. Animal subjects: All authors have confirmed that this study did not involve animal subjects or tissue. Conflicts of interest: In compliance with the ICMJE uniform disclosure form, all authors declare the following: Payment/services info: This study was supported by a grant from university research council, the Aga Khan University, Karachi, Pakistan. Grant ID: 031018SURG. Financial relationships: All authors have declared that they have no financial relationships at present or within the previous three years with any organizations that might have an interest in the submitted work. Other relationships: All authors have declared that there are no other relationships or activities that could appear to have influenced the submitted work.

\section{Acknowledgements}

This study was supported by a grant from university research council, the Aga Khan University, Karachi, Pakistan. Grant ID: 031018SURG.

\section{References}

1. Ferlay J, Soerjomataram I, Dikshit R, et al.: Cancer incidence and mortality worldwide: sources, methods and major patterns in GLOBOCAN 2012. Int J Cancer. 2015, 136:359-386. 10.1002/ijc. 29210

2. Bhurgri Y: Cancer of the oral cavity - trends in Karachi South (1995-2002) . Asian Pac J Cancer Prev. 2005, 6:22-26.

3. Bhurgri $Y$, Bhurgri A, Nishter S, et al.: Pakistan--country profile of cancer and cancer control 1995-2004. J Pak Med Assoc. 2006, 56:124-130.

4. Vogelstein B, Papadopoulos N, Velculescu VE, et al.: Cancer genome landscapes. Science. 2013, 339:1546-1558. 10.1126/science.1235122

5. Chaturvedi P: Areca nut or betel nut control is mandatory if India wants to reduce the burden of cancer especially cancer of the oral cavity. Int J Head Neck Surg. 2010, 1:17-20. 10.5005/jpjournals-10001-1003

6. Gupta PC, Ray CS: Epidemiology of betel quid usage. Ann Acad Med Singapore. 2004, 33:3136.

7. Khawaja MR, Mazahir S, Majeed A, et al.: Knowledge, attitude and practices of a Karachi slum population regarding the role of products of betel, areca and smokeless tobacco in the etiology of head \& neck cancers. J Pak Med Assoc. 2005, 55:S41.

8. Rothenberg SM, Ellisen LW: The molecular pathogenesis of head and neck squamous cell carcinoma. J Clin Invest. 2012, 122:1951-1957. 10.1172/JCI59889

9. Surget S, Khoury MP, Bourdon JC: Uncovering the role of p53 splice variants in human malignancy: a clinical perspective. Onco Targets Ther. 2013, 7:57-68. 10.2147/OTT.S53876

10. de Stanchina E, McCurrach ME, Zindy F, et al.: E1A signaling to p53 involves the p19(ARF) tumor suppressor. Genes Dev. 1998, 12:2434-2442.

11. Greenblatt MS, Bennett WP, Hollstein M, et al.: Mutations in the p53 tumor suppressor gene: clues to cancer etiology and molecular pathogenesis. Cancer Res. 1994, 54:4855-4878.

12. Lane DP, Hall PA: MDM2--arbiter of p53's destruction. Trends Biochem Sci. 1997, 22:372374. 10.1016/S0968-0004(97)01119-5

13. Mork J, Glattre E: Squamous cell carcinomas of the head and neck in Norway, 1953-92: an epidemiologic study of a low-risk population. Cancer Causes Control. 1998, 9:37-48. 10.1023/A:1008845219266

14. Ali SMA, Awan MS, Ghaffar S, et al.: TP53 protein overexpression in oral squamous cell carcinomas (OSCC): correlation with histologic variables and survival outcome in Pakistani patients. Oral Surgery. 2010, 3:83-95. 10.1111/j.1752-248X.2010.01089.x

15. Bishop JM: Molecular themes in oncogenesis. Cell. 1991, 64:235-248. 10.1016/0092- 
16. Vokes EE, Weichselbaum RR, Lippman SM, et al.: Head and neck cancer. N Engl J Med. 1993, 328:184-194. 10.1056/NEJM199301213280306

17. Ostwald C, Gogacz P, Hillmann T, et al.: p53 mutational spectra are different between squamous-cell carcinomas of the lip and the oral cavity. Int J Cancer. 2000, 88:82-86. 10.1002/1097-0215(20001001)88:1<82::AID-IJC13>3.0.CO;2-N

18. Saranath D, Tandle AT, Teni TR, et al.: p53 inactivation in chewing tobacco-induced oral cancers and leukoplakias from India. Oral Oncol. 1999, 35:242-250. 10.1016/S13688375(98)00110-9

19. Su SC, Lin CW, Liu YF, et al.: Exome sequencing of oral squamous cell carcinoma reveals molecular subgroups and novel therapeutic opportunities. Theranostics. 2017, 7:1088-1099. 10.7150/thno.18551

20. Ko Y, Abel J, Harth V, et al.: Association of CYP1B1 codon 432 mutant allele in head and neck squamous cell cancer is reflected by somatic mutations of p53 in tumor tissue. Cancer Res. 2001, 61:4398-4404.

21. Ahmed AA, Etemadmoghadam D, Temple J, et al.: Driver mutations in TP53 are ubiquitous in high grade serous carcinoma of the ovary. J Pathol. 2010, 221:49-56. 10.1002/path.2696

22. Piffko J, Bankfalvi A, Tory K, et al.: Molecular assessment of p53 abnormalities at the invasive front of oral squamous cell carcinomas. Head Neck. 1998, 20:8-15. 10.1002/(SICI)10970347(199801)20:1<8::AID-HED2>3.0.CO;2-8

23. Nylander K, Schildt EB, Eriksson M, et al.: PCNA, Ki-67 p53, bcl-2 and prognosis in intraoral squamous cell carcinoma of the head and neck. Anal Cell Pathol. 1997, 14:101-110. $10.1155 / 1997 / 591251$

24. Sauter ER, Ridge JA, Litwin S, et al.: Pretreatment $\mathrm{p} 53$ protein expression correlates with decreased survival in patients with end-stage head and neck cancer. Clin Cancer Res. 1995, $1: 1407-1412$.

25. Poeta ML, Manola J, Goldwasser MA, et al.: TP53 mutations and survival in squamous-cell carcinoma of the head and neck. N Engl J Med. 2007, 357:2552-2561. 10.1056/NEJMoa073770

26. Nylander K, Dabelsteen E, Hall PA: The p53 molecule and its prognostic role in squamous cell carcinomas of the head and neck. J Oral Pathol Med. 2000, 29:413-425. 10.1034/j.16000714.2000.290901.x

27. Field JK, Pavelic ZP, Spandidos DA, et al.: The role of the p53 tumor suppressor gene in squamous cell carcinoma of the head and neck. Arch Otolaryngol Head Neck Surg. 1993, 119:1118-1122. 10.1001/archotol.1993.01880220064009 